\title{
Platelet activating factor-induced mast cell degranulation is inhibited by rupatadine, and to a lower extent by levocetirizine and desoratadine, in a mast cell line (LAD-2)
}

\author{
Joaquim Mullol, Rosa Muñoz-Cano, I Torres-Atencio, E Ainsua, M Martin, J Sanchez-Lopez, Joan Bartra,
} Cesar Picado, Antonio Valero

From 9th Symposium of Experimental Rhinology and Immunology of the Nose (SERIN 2013) Leuven, Belgium. 21-23 March 2013

\section{Background}

Platelet activating factor (PAF) is a lipid mediator that appears to be involved in the pathophysiology of several allergic reactions such as anaphylaxis and potentially urticaria and allergic rhinitis. The role of rupatadine, a drug with dual antihistamine and anti-PAF effect, in mast cell (MC) degranulation is not known. The objective of this study was to investigate the expression of PAF receptors and the effect of rupatadine on PAFinduced MC degranulation compared with other second generation antihistamines (desloratadine, levocetizine) and a pure specific PAF inhibitor in a human mast cell line (LAD-2).

\section{Methodology}

MC degranulation was evaluated by the â-hexosaminidase and histamine release while PAF receptor expression was evaluated by western blot. After stimulation with PAF in a dose-response and time course manner, the optimal PAF conditions to induce LAD-2 degranulation were identified (10 $\mu \mathrm{M}$ and 30 minutes). The effects of rupatadine, desloratadine, and levocetirizine (from $1 \mu \mathrm{M}$ to $100 \mu \mathrm{M}$ ) on PAF-induced LAD-2 degranulation were investigated. The inhibitory effect of CV6209 (specific anti-PAF) at $2 \mu \mathrm{M}$ was used as positive control in all experiments.

\section{Results}

Protein expression of the PAF receptor was found in LAD- 2 cells. Rupatadine ( 5 to $10 \mu \mathrm{M}, \mathrm{p}<0.005$ ) and levocetirizine $(5 \mu \mathrm{M}, \mathrm{p}<0.01)$ but not desloratadine inhibited
PAF-induced â-hexosaminidase release. Rupatadine ( 1 to $10 \mu \mathrm{M}, \mathrm{p}<0.01$ ), levocetirizine ( 1 to $25 \mu \mathrm{M}, \mathrm{p}<0.05$ ), and desloratadine $(10 \mu \mathrm{M}, \mathrm{p}<0.05)$ also inhibited PAFinduced histamine release.

\section{Conclusions}

This study shows that the ant-H1 compunds rupatadine, and to a lower extent levocetirizine and desloratadine, have an anti-PAF effect in the mast cell line LAD-2, suggesting that rupatadine could be more effective than other antihistamine drugs in those allergic disorders where PAF may act as an important inflammatory mediator.

Published: 16 July 2013

doi:10.1186/2045-7022-3-S2-06

Cite this article as: Mullol et al: Platelet activating factor-induced mast cell degranulation is inhibited by rupatadine, and to a lower extent by levocetirizine and desoratadine, in a mast cell line (LAD-2). Clinical and Translational Allergy 2013 3(Suppl 2):06. 